\title{
Long-term efficacy of transvaginal high uterosacral ligament suspension for middle-compartment defect-based pelvic organ prolapse
}

\author{
Wenying Wang", Yinghui Zhang", Wenjie Shen, Ke Niu, Yongxian Lu \\ Department of Obstetrics and Gynecology, Fourth Medical Center, General Hospital of People's Liberation Army, Beijing, China \\ Contributions: (I) Conception and design: Y Lu; (II) Administrative support: W Shen; (III) Provision of study materials or patients: W Wang, Y \\ Zhang; (IV) Collection and assembly of data: K Niu; (V) Data analysis and interpretation: W Wang, Y Zhang; (VI) Manuscript writing: All authors; \\ (VII) Final approval of manuscript: All authors. \\ "These authors contributed equally to this work. \\ Correspondence to: Yongxian Lu. Department of Obstetrics and Gynecology, Fourth Medical Center, General Hospital of People's Liberation Army, \\ Beijing 100048, China. Email: yongxianlu@qq.com.
}

Background: We aim to assess the long-term efficacy of transvaginal high uterosacral ligament suspension (HUS) procedure for middle compartment defect-based pelvic organ prolapse (POP).

Methods: We performed a retrospective review of 84 women with middle-compartment defect-based POP who underwent transvaginal HUS as the primary surgical treatment without mesh augmentation from January 2007 to January 2019. All 84 patients manifested $\geq$ grade-II middle-compartment defectbased POP. Follow-up visits were performed 2, 6 and 12 months after surgery and then annually, including questionnaires and clinical examination using pelvic organ prolapse quantitation system (POP-Q). Surgical success required to fulfill all three of these criteria: (I) anterior or posterior vaginal wall prolapsed the leading edge of $0 \mathrm{~cm}$ or less and apex of $1 / 2$ total vaginal length or less; (II) the absence of POP symptoms as reported on the PFDI-20 question No. 3 ("do you usually have a bulge or something falling out that you can see or feel in your vaginal area?”); and (III) no prolapse re-operations or pessary use during the study period. Results: Of 84 women, 56 cases $(66.7 \%, 56 / 84)$ were evaluated at a $\geq 5$-year follow-up. The 5-year recurrence rates for patients with prolapse of either the anterior vaginal wall, vaginal vault, or posterior vaginal wall, or prolapses in multiple sites, were $7.1 \%$ (4/56), 0, 1.8\% (1/56), and 3.6\% (2/56), respectively. The surgery success rate was $87.5 \%$ (49/56). None of the recurrent women underwent retreatment. The satisfaction rate was $91.1 \%(51 / 56)$.

Conclusions: Transvaginal HUS without mesh augmentation is a safe and effective procedure in the surgical treatment of patients with middle-compartment defects. Anatomical, functional, and subjective outcomes were very satisfactory.

Keywords: Pelvic organ prolapse (POP); high-uterosacral ligament suspension; gynecologic surgical procedures; treatment

Submitted Sep 27, 2020. Accepted for publication Dec 04, 2020.

doi: 10.21037/atm-20-7296

View this article at: http://dx.doi.org/10.21037/atm-20-7296

\section{Introduction}

Pelvic organ prolapse (POP) is defined as the descent of any vaginal compartment (1). The surgical treatment of POP mainly includes native tissue repair or implantation of mesh to strengthen the pelvic support Native tissue repair aims to correct an existing anatomical lesion using the tissue itself. Although synthetic materials have better cure rates, complications are still a thorny problem in 
clinics. The FDA announced the complications and adverse events of transvaginal mesh in treating POP in 2011. There is no obvious evidence for the superiority of using mesh compared with native tissue. The American College of Obstetrics and Gynecology (ACOG) and the International Urogynecological Association (IUGA) currently recommend synthetic meshes primarily for women at high risk of recurrent prolapse and for cases of recurrence $(2,3)$. Currently, there is a renewed interest in transvaginal native tissue repair due to the low cost and insufficient mesh-related complications (4). High uterosacral ligament suspension (HUS) is a necessary surgery for native tissue repair for POP. In recent years, many reports on the longterm efficacy of transvaginal HUS in POP treatment have proved the efficacy in the transvaginal management of prolapse. Polypropylene mesh is often used to the anterior wall of the vagina at the same time, which can assist in the reduction of middle pelvic defects to a certain extent. However, there are few reports on whether autologous tissue repair with transvaginal HUS suspension as the main surgical method is effective in the treatment of POP. The purpose of this study was to explore the long-term effect of HUS without mesh in the treatment of middlecompartment defect-based POP.

We present the following article in accordance with the STROBE reporting checklist (available at http://dx.doi. org/10.21037/atm-20-7296).

\section{Methods}

\section{Research subjects}

For this study, women middle-compartment defect-based POP who underwent transvaginal HUS as the primary surgical treatment from January 2007 to January 2019 in the Department of Gynecology of the Fourth Medical Center of the People's Liberation Army General Hospital were identified. Patients have follow-up assessments at postoperative months 2,6 , and 12 , and annually after that. We retrospectively analyzed the clinical data. So far, 84 cases have been systematically followed up for more than half a year $(100 \%, 84 / 84), 77$ cases for more than 2 years $(91.7 \%, 77 / 84)$, and 56 cases for more than 5 years $(66.7 \%$, $56 / 84)$. The longest follow-up period is 12 years.

The complete urogenital examination was performed, and POP staged according to the Pelvic Organ Prolapse Quantification (POP-Q) system (5). All 84 patients manifested $\geq$ grade-II middle-compartment defect-based POP-Q.
This study was approved by the ethics committee of General Hospital of People's Liberation Army. All procedures performed in this study involving human participants were in accordance with the Declaration of Helsinki (as revised in 2013). Individual consent for this retrospective analysis was waived.

\section{Surgical methods}

Routine cervical cytology and pelvic and renal tract ultrasonography were conducted to exclude cervical lesions and pelvic and renal tract lesions. The same chief surgeon conducted all procedures and 2-4 associate chief surgeons. Once the hysterectomy with or without oophorectomy was performed, Two Breisky-Navratil retractors were placed in the vaginal and help with visualization and palpation of the uterosacral ligament. The uterosacral ligament was identified and grasped $1-3 \mathrm{~cm}$ medial and posterior to the ischial spine with an allis clamp. The ligament was spiral sutured above the ischial spine with No. 7 or 10 silk thread. This was repeated on the contralateral side. Then use the same suture to fix the vaginal cuff to ligaments. Specific surgical procedures were as described in an earlier study (6). For the patients with $\geq$ grade-II anterior and posterior vaginal wall prolapse after the restoration of the vaginal vault, added native tissue reconstruction of the anterior and posterior vaginal walls were performed. Table 1 depicts the other POP-related procedures performed during the same period. Cystoscopy was used to assess postoperative ureteral patency.

\section{Follow-up and evaluation}

Outpatient follow-up was performed at 2, 6, and 12 months after transvaginal HUS, then annually after that. The indicative points of POP-Q were measured at the postoperative follow-up. The patient's global impression of improvement (PGI-I) - specifically for POP patientswas adopted to assess subjective satisfaction. The PGI-I was divided into 7-point scales: 1 , very much better; 2 , much better; 3 , slightly better; 4 , no change; 5 , slightly worse; 6 , much worse; 7 , very much worse (7). We used the pelvic floor distress inventory (PFDI-20) and pelvic floor impact questionnaire short form (PFIQ-7) to assess the improvement of symptoms and quality of life in the patients: the higher the score, the greater the impact of POP on patients.

Our study assessed perioperative endpoints included estimated blood loss, postoperative morbidity [body 
Table 1 Other surgical methods performed concurrently with transvaginal HUS

\begin{tabular}{lcc}
\hline Surgical methods & Cases & Percentage (\%) \\
\hline Transvaginal hysterectomy & 82 & 97.6 \\
Transvaginal trachelectomy & 2 & 2.4 \\
Unilateral or bilateral salpingo- & 43 & 51.2 \\
oophorectomy & & \\
Anterior vaginal wall reconstruction & 28 & 33.3 \\
Posterior vaginal wall reconstruction & 45 & 53.6 \\
Rectocele repair, perineorrhaphy & 42 & 50 \\
Tension-free vaginal tape & 30 & 35.7 \\
McCall culdoplasty procedure & 4 & 4.8 \\
\hline
\end{tabular}

HUS, high uterosacral ligament suspension.

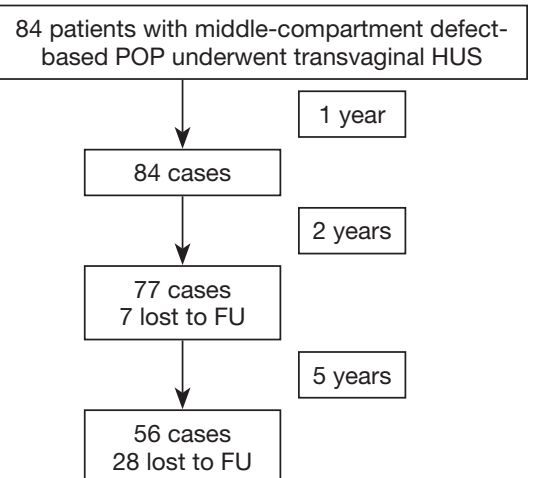

Figure 1 Progress of patients across the study period. POP, pelvic organ prolapse; HUS, high uterosacral ligament suspension; FU, follow-up.

temperature over $38^{\circ} \mathrm{C}$ twice (4 hours apart) within 24 hours after surgery], and perioperative complications.

We adopted the criteria for successful surgery proposed by Vallabh-Patel et al. (8), including (I) $\leq 0 \mathrm{~cm}$ prolapse for the leading edge and prolapse $\leq 1 / 2$ of the total vaginal length from the vaginal vault; (II) absence of related POP symptoms as reported on the third question of our survey ("Do you usually have a bulge or something falling from your vaginal area that you can see or feel?"), of the pelvic floor distress inventory-short form 20 (PFDI-20); and (III) neither prolapse re-operation nor pessary use.

\section{Statistical analysis}

We used the SAS University Edition for statistical analysis.
Normally distributed measurement data are presented as means \pm standard deviation $(\bar{x} \pm s)$, while non-normally distributed measurement data are presented as medians ( $M$, interquartile range). Counting data is presented as an absolute number or percentage. Comparisons of the counting data were performed using the Chi-square test, and Fisher's exact test was used if the expected number of cells was less than five and greater than $20 \%$. The generalized estimating equation (GEE) was used to analyze the differences between different factors and different measurement points across time for the repeated-measurement data. $\mathrm{P}<0.05$ was considered statistically significant.

\section{Results}

\section{Patients}

Of the 84 POP patients, the median age was 59 (range, 38-87) years; the median body mass index (BMI) was 23.4 (17.0-34.8) $\mathrm{kg} / \mathrm{m}^{2}$; and the median numbers for pregnancies and births were $3[1-8]$ and $2[1-8]$, respectively. None of the patients had a history of hormone replacement therapy, and there were 59 cases $(70 \%, 59 / 84)$ of menopause. There were also 51 cases $(60.7 \%, 51 / 84)$ with one or more medical diseases, including 31 cases of hypertension or coronary heart disease, 10 cases of diabetes, 5 cases of cerebrovascular disease or prior cerebral infarction, 3 cases of chronic bronchitis, and chronic asthma, and 1 case of chronic renal insufficiency. Also, there were 19 cases of uterine fibroids or adenomyosis, 5 cases of benign ovarian cysts, 1 case of stage-IA endometrial cancer, 1 case of atypical endometrial hyperplasia, and 1 case of dysfunctional climacteric uterine bleeding. Two patients underwent subtotal hysterectomies. Figure 1 is a flowchart of the study.

Of the 84 patients, 76 patients $(90.5 \%)$ showed anterior vaginal wall prolapse, and 75 patients $(89.3 \%)$ had posterior vaginal wall prolapse. The point $\mathrm{C}$ (cervix or vaginal cuff) for the POP-Q of patients with both anterior vaginal wall prolapse and posterior vaginal wall prolapse was $\geq$ point $\mathrm{B}$ anterior (Ba) or point $\mathrm{B}$ posterior $(\mathrm{Bp})$. Table 2 depicts the specific POP staging that we used in our study. The preoperative evaluation found 35 cases $(41.7 \%, 35 / 84)$ of stress urinary incontinence (SUI) and 1 case $(1.2 \%, 1 / 84)$ of mixed urinary incontinence (MUI).

\section{Perioperative conditions}

Transvaginal HUS was completed in all patients. Native tissue reconstruction of the anterior vaginal wall was performed in 
Table 2 Preoperative POP-Q grading of 84 patients with moderate-to-severe middle- compartment defect-based POP

\begin{tabular}{|c|c|c|c|c|c|c|c|c|}
\hline Prolapse site & \multicolumn{2}{|r|}{1} & \multicolumn{2}{|r|}{ II } & \multicolumn{2}{|r|}{ III } & \multicolumn{2}{|r|}{ Total } \\
\hline Vaginal vault & 0 & 0 & 46 & 54.8 & 38 & 45.2 & 84 & 100 \\
\hline Anterior vaginal wall & 11 & 13.1 & 34 & 40.5 & 31 & 36.9 & 76 & 90.5 \\
\hline Posterior vaginal wall & 16 & 19 & 33 & 39.3 & 26 & 30.9 & 75 & 89.3 \\
\hline
\end{tabular}

POP-Q, Pelvic Organ Prolapse Quantification; POP, pelvic organ prolapse.

Table 3 Comparison of preoperative and postoperative positions of POP-Q indicative points in 84 patients $(\mathrm{cm})$

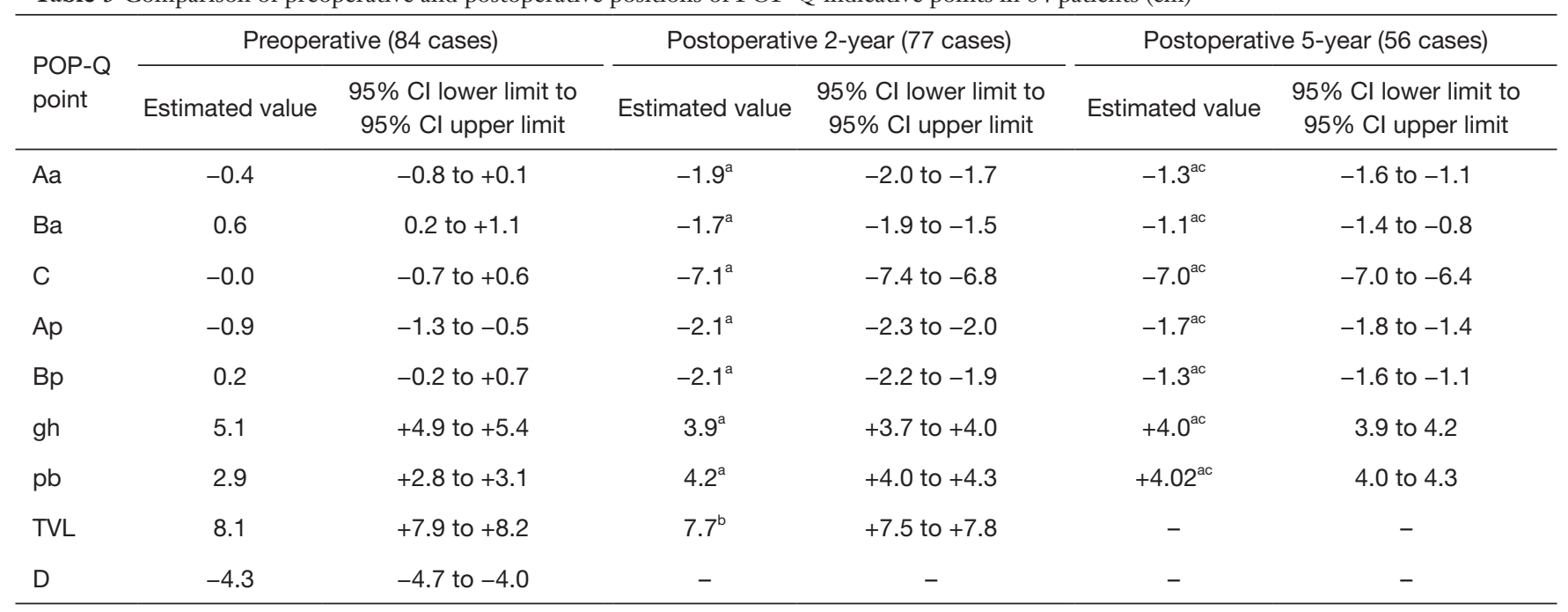

Compared with the preoperative value, ${ }^{a}, \mathrm{P}<0.05,{ }^{b}, \mathrm{P}>0.05$; compared with the postoperative 2-year value, ${ }^{\mathrm{c}}, \mathrm{P}<0.05$; -no such item. POP-Q, Pelvic Organ Prolapse Quantification; Aa, A anterior; Ba, B anterior; Ap, A posterior; Bp, B posterior; C, cervix or vaginal cuff; gh, genital hiatus; $\mathrm{pb}$, perineal body; TVL, total vaginal length; $\mathrm{D}$, posterior fornix.

28 cases $(33.3 \%, 28 / 84)$, and reconstruction of the posterior vaginal wall was performed in 44 cases $(52.4 \%, 44 / 84)$. The median operation time is 28.6 (range, 21-36) min, the median estimated blood loss was $100 \mathrm{~mL}$ (range, 50-200 $\mathrm{mL}$ ), and no patient needed a blood transfusion. One case $(1.2 \%, 1 / 84)$ of ureteral obstruction was resolved after removing and re-stitching the suture lines of the uterosacral ligament. The postoperative morbidity was $2.4 \%(2 / 84)$.

\section{Objective therapeutic efficacy after surgery}

The POP-Q indicative points $\mathrm{A}$ anterior (Aa), Ba, A posterior (Ap), $\mathrm{Bp}$, and $\mathrm{C}$ were significantly higher than before surgery, and significant differences were found between the preoperative and postoperative 2- and 5-year values $(\mathrm{P}<0.05)$. At five years postoperatively, seven patients $(12.5 \%, 7 / 56)$ who completed their $\geq 5$-year follow-up exhibited the leading edge of the anterior and posterior vaginal walls beyond the hymen, with $\leq \mathrm{a} 1$-cm length between the leading edge and the hymen. The 5-year recurrence rates for patients with prolapse of either the anterior vaginal wall, vaginal vault, or posterior vaginal wall, or prolapses in multiple sites, were $7.1 \%$ (4/56), 0 , $1.8 \%(1 / 56)$, and $3.6 \%(2 / 56)$, respectively. None of the patients manifested descent of the vaginal vault for more than $1 / 2$ of the vaginal length. The genital hiatus (GH) was significantly reduced compared with the preoperative level $(\mathrm{P}<0.05)$, and the perineal body $(\mathrm{pb})$ was significantly increased compared with the preoperative level $(\mathrm{P}<0.05)$ (Table 3). At the postoperative 5-year follow-up visit, the operation's overall success rate concerning the three criteria was $87.5 \%$ (49/56). The objective success rates of surgery for patients with anterior vaginal wall prolapse, vaginal vault prolapse, or posterior vaginal wall prolapse were $89.3 \%$ 
Table 4 Comparison of postoperative recurrence rates in 56 patients with 5-year follow-up and different preoperative POP-Q scores

\begin{tabular}{lccccc}
\hline \multirow{2}{*}{ Category } & \multicolumn{2}{c}{ Anterior vaginal wall (preoperative) } & & \multicolumn{2}{c}{ Posterior vaginal wall (preoperative) } \\
\cline { 2 - 3 } Postoperative recurrence rate & $19 \%(4 / 21)$ & $5.7 \%{ }^{\mathrm{b}}(2 / 35)$ & & $11.8 \%(2 / 17)$ & $2.6^{\mathrm{b}}(1 / 39)$ \\
\hline
\end{tabular}

Compared with POP-Q $\geq 11 \mathrm{l},{ }^{\mathrm{b}}, \mathrm{P}>0.05$. POP-Q, Pelvic Organ Prolapse Quantification.

Table 5 Comparison of preoperative and postoperative PFDI-20 and PFIQ-7 scores in the 84 patients

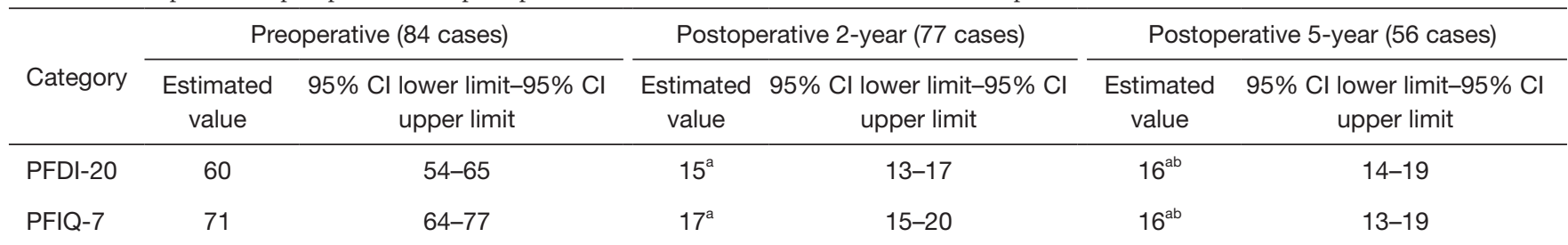

a, compared with preoperative value, $\mathrm{P}<0.05 ;{ }^{b}$, compared with postoperative 2 -year value, $\mathrm{P}>0.05$. PFIQ-7, pelvic floor impact questionnaire short form; PFDI-20, pelvic floor distress inventory-20.

(50/56), 100\% (56/56), and 94.6\% (53/56), respectively.

The recurrence rate for patients with preoperative $\geq$ grade-III anterior vaginal wall prolapse was 19\% (4/21), while the recurrence rate for patients with preoperative $\leq$ grade-II anterior vaginal wall prolapse was 5.7\% (2/35) (NS, not significantly different). The recurrence rate for patients with preoperative $\geq$ grade-III posterior vaginal wall prolapse was $11.8 \%$ (2/17), which was significantly higher than the recurrence rate for patients $(2.6 \%, 1 / 39)$ with $\leq$ grade-II posterior vaginal wall prolapse preoperatively (NS). However, the lengths between the leading edge and the hymen of the prolapsed site in the recurrence mentioned above cases were $\leq 1 \mathrm{~cm}$; and the patients with prolapse recurrence did not require re-operation or a pessary (Table 4).

\section{Assessment of subjective therapeutic efficacy}

At the 5-year postoperative follow-up, the PGI-I scale was satisfactory in 46 cases, and the satisfaction rate was $91.1 \%(51 / 56)$. We found 5 cases of dissatisfaction in the PGI-I scale, including 3 cases with prolapse symptoms, 1 case of suture exposure in the vaginal vault, and 1 case of MUI with no improvement in the symptoms of urgency after anti-urinary incontinence procedures. The PFDI-20 and PFIQ-7 scores at the postoperative 2- and 5-year followups were significantly lower than the preoperative levels $(\mathrm{P}<0.05)$; however, no significant differences in the PFDI20 and PFIQ-7 scores were found between the postoperative 1 -year and postoperative 5-year visits $(\mathrm{P}>0.05)$ (Table 5). Importantly, 14 patients with preoperative dysuria showed relief of symptoms after surgery. We observed that symptoms of stress urinary incontinence in 1 case of MUI disappeared, but the symptoms of urgency did not improve after the antiurinary incontinence procedures. Rather, the symptoms of urgency were only relieved after the behavioral intervention and oral administration of anticholinergic drugs.

\section{Discussion}

Uterosacral ligaments are considered safe, effective, and durable as suspending structures for repairing apical prolapse (9). Many findings support using USLs as suspending structures for apical repair (10). A cadaveric study demonstrated that the intermediate portion of the USL is the optimal site for suspension, which can sustain more than $17 \mathrm{~kg}$, and it is located at a mean $2.3 \mathrm{~cm}$ away from the ureter (11). These results were like those of Barber et al. (12). However, the current study's success rate was lower than our previously reported success rate $(91.3 \%)$ at a mean of 9 years after HUS (13). Our earlier study's higher success rate was related to the intraoperative application of synthetic mesh for those patients with severe anterior vaginal wall prolapse.

Clinically, the occurrence of prolapse is often not a single pelvic compartment but multiple simultaneously. Rooney et al. (14) also found that point $\mathrm{C}$ was strongly correlated with $\mathrm{Ba}$ and moderately correlated with $\mathrm{Bp}$ when evaluating the relationship between the middle compartment and anterior/posterior wall prolapse by POP-Q. Summers et al. (15) also found that changes in the apical support 
caused at least $50 \%$ of the changes in the anterior pelvic support structure, and there was a strong correlation between the apical support defect and the paravaginal support defect. These studies show the presence of anterior and posterior wall bulge in moderate and severe POP is closely related to middle compartment pelvic defects and emphasize the necessity of reconstruction of apical support during severe POP; otherwise, it is susceptible to lead to the failure of repair surgery in other parts $(14,16)$

Using native tissue repair in the middle compartment of pelvic prolapse can play a complementary role in anterior wall repair. The results of a study of nearly 3,000 prolapse operations showed that compared with single anterior wall repair, patients who underwent middle pelvic defect repair had a lower 10 -year re-operation rate $(11.6 \% v s$. $20.2 \%$ ) (17). Milani's research shows that the total recurrence rate was $13.7 \%$, with the anterior compartment being the most frequent $(9.4 \%)$, whereas re-operation for symptomatic prolapse recurrence was required in only $1 \%$ of patients (18). For POP patients, the most meaningful criteria for successful treatment are the symptoms associated with prolapse, especially the improvement or disappearance of prolapse signs and symptoms (19). When strict anatomic criteria are adopted-i.e., POP-Q 0 or I stage-the success rate for autologous tissue reconstruction of the anterior vaginal wall is usually between $37 \%$ and $64 \%$, application of more clinically relevant criteria, including "no prolapse beyond the hymen" and "no vaginal prolapse symptoms", the rate of re-operation due to prolapse recurrence remains only $5-10 \%$ (20). In the present study, we used transvaginal HUS combined with native tissue reconstruction of anterior and posterior vaginal walls to treat patients with moderateto-severe middle-compartment defects. We also followed the more clinically meaningful criteria for a successful surgery, obtaining a satisfactory long-term aim and subjective outcomes. The anterior vaginal wall is the site of the greatest recurrence of POP after surgery. Our results also suggest patients with severe preoperative prolapse have an increased risk of postoperative recurrence. The above result was substantiated by a meta-analysis of transvaginal HUS performed by Margulies et al. (21).

In the present study, to minimize the risk of postoperative prolapse recurrence, we used transvaginal HUS combined with autologous tissue reconstruction of the anterior and posterior vaginal walls in patients with predominantly middle- compartment defects, i.e., patients with the POP-Q points $\mathrm{C}, \geq \mathrm{Ba}$ or $\mathrm{Bp}$; and in patients with significant alleviation in anterior and posterior vaginal wall prolapse after the restoration of the vaginal vault. Therefore, these patients achieved satisfactory outcomes for five years. Although patients with a POP-Q $\geq$ III still had a recurrence, the 5-year recurrence rate was relatively low (12.5\%); and the severity of prolapse was relatively mild, with their $\mathrm{Ba}$ or $\mathrm{Bp} \leq 1 \mathrm{~cm}$. We have no cases needing re-operation or a pessary due to prolapse recurrence. The limitation of this study is that the sample size is a little small, but these data are comparable to the $0.7 \%$ re-operation rate described by Shull $\mathrm{L}$ in their series (22).

In addition to infection and bleeding, the most common transvaginal HUS surgery complications are ureteral injury, while the rare complications are neurosensory injury and uterine artery injury. The incidence of neuralgia after transvaginal HUS was $1.6-6.9 \%(12,23)$. In our series, ureteral kinking occurred in $1.2 \%$. This rate is comparable to $1.8 \%$ of ureteral obstruction described in a USL suspension systematic review (21). Anterior repair is also recognized as an independent added risk factor for ureteral kinking (24). For the prevention of complications, the suture is recommended to avoid excessive depth and deviation. Maldonado et al. suggested that when the ischial spine is used as an anatomical sign, the distance between the suture and ischial spine is more than $4.6 \mathrm{~cm}$, the risk of sacral nerve $\mathrm{S} 3$ injury will be increased (25).

In conclusion, we suggest that transvaginal HUS combine with autologous tissue reconstruction to be performed in the patients with the anterior and posterior vaginal with predominantly middle-compartment defects and a significant alleviation of anterior and posterior vaginal wall prolapse after the restoration of the vaginal vault. Uterosacral ligament suspension is a safe and effective surgical treatment procedure for middle-compartment defects POP. Anatomical, functional, and subjective outcomes were satisfactory.

\section{Acknowledgments}

Funding: Outcome Fund program: National Science and Technology Infrastructure Program (2014BAI05B02).

\section{Footnote}

Reporting Checklist: The authors have completed the STROBE reporting checklist. Available at http://dx.doi. org/10.21037/atm-20-7296

Data Sharing Statement: Available at http://dx.doi. 
org/10.21037/atm-20-7296

Conflicts of Interest: All authors have completed the ICMJE uniform disclosure form (available at http://dx.doi. org/10.21037/atm-20-7296). The authors have no conflicts of interest to declare.

Ethical Statement: The authors are accountable for all aspects of the work in ensuring that questions related to the accuracy or integrity of any part of the work are appropriately investigated and resolved. This study was approved by the ethics committee of General Hospital of People's Liberation Army. All procedures performed in this study involving human participants were in accordance with the Declaration of Helsinki (as revised in 2013). Individual consent for this retrospective analysis was waived.

Open Access Statement: This is an Open Access article distributed in accordance with the Creative Commons Attribution-NonCommercial-NoDerivs 4.0 International License (CC BY-NC-ND 4.0), which permits the noncommercial replication and distribution of the article with the strict proviso that no changes or edits are made and the original work is properly cited (including links to both the formal publication through the relevant DOI and the license). See: https://creativecommons.org/licenses/by-nc-nd/4.0/.

\section{References}

1. Haylen BT, Maher CF, Barber MD, et al. An International Urogynecological Association (IUGA)/International Continence Society (ICS) joint report on the terminology for female pelvic organ prolapse (POP). Int Urogynecol J 2016;27:655-84.

2. da Silveira SDRB, Auge AP, Jarmy-Dibella ZI, et al. A multicenter, randomized trial comparing pelvic organ prolapse surgical treatment with native tissue and synthetic mesh: A 5-year follow-up study. Neurourol Urodyn 2020;39:1002-11.

3. Food and Drug Administration (2011) FDA safety communication: UPDATE on serious complications associated with transvaginal placement of surgical mesh for pelvic organ prolapse. Silver Spring (MD): FDA. Available online: http://www.fda.gov/ MedicalDevices/Safety/ AlertsandNotices/ucm262435.htm. Retrieved 7 Jan 2012.

4. Cheon C, Maher C. Economics of pelvic organ prolapse surgery. Int Urogynecol J 2013;24:1873-6.

5. Bump RC, Mattiasson A, Bø K, et al. The standardization of terminology of female pelvic organ prolapse and pelvic floor dysfunction. Am J Obstet Gynecol 1996;175:10-7.

6. Lu YX, Wang J, Shen WJ, et al. Long-term outcomes of the high vaginal uterosacral ligament suspension in treatment of the severe pelvic organ prolapse. Zhonghua Fu Chan Ke Za Zhi 2013;48:564-9.

7. Srikrishna S, Robinson D, Cardozo L. Validation of the Patient Global Impression of Improvement (PGI-I) for urogenital prolapse. Int Urogynecol J 2010;21:523-8.

8. Vallabh-Patel V, Saiz C, Salamon C. Subjective and objective outcomes of robotic and vaginal high uterosaral ligament suspension. Female Pelvic Med Reconstr Surg 2016;22:420-4.

9. Silva WA, Pauls RN, Segal JL, et al. Uterosacral ligament vault suspension: five-year outcomes. Obstet Gynecol 2006;108:255-63.

10. Gabriel B, Denschlag D, Göbel H, et al. Uterosacral ligament in postmenopausal women with or without pelvic organ prolapse. Int Urogynecol J Pelvic Floor Dysfunct 2005;16:475-9.

11. Buller JL, Thompson JR, Cundiff GW, et al. Uterosacral ligament: description of anatomic relationships to optimize surgical safety. Obstet Gynecol 2001;97:873-9.

12. Barber MD, Brubaker L, Burgio KL, et al. Comparison of 2 transvaginal surgical approaches and perioperative behavioral therapy for apical vaginal prolapse: the OPTIMAL randomized trial. JAMA 2014;311:1023-34.

13. Duan L, Lu YX, Shen WJ, et al. Long-term effectiveness of transvaginal high uterosacral ligament suspension. Zhonghua Fu Chan Ke Za Zhi 2017;52:363-8.

14. Rooney K, Kenton K, Mueller ER, et al. Advanced anterior vaginal wall prolapse is highly correlated with apical prolapse. Am J Obstet Gynecol 2006;195:1837-40.

15. Summers A, Winkel LA, Kussain H, et al. The relationship between anterior and apical compartment support. Am J Obstet Gynecol. 2006;194:1438-43.

16. Barber MD, Maher C. Apical prolapse. Int Urogynecol J 2013;24:1815-33.

17. Eilber KS, Alperin M, Khan A, et al. Outcomes of vaginal prolapse surgery among female Medicare beneficiaries: the role of apical support. Obstet Gynecol 2013;122:981-7.

18. Milani R, Frigerio M, Cola A, et al. Outcomes of Transvaginal High Uterosacral Ligaments Suspension: Over 500-Patient Single-Center Study. Female Pelvic Med Reconstr Surg 2018;24:203-6.

19. Barber MD, Brubaker L, Nygaard I, et al. Defining success after surgery for pelvic organ prolapse. Obstet Gynecol 2009;114:600-9. 


\section{Page 8 of 8}

20. Siff LN, Barber MD. Native Tissue Prolapse Repairs: Comparative Effectiveness Trials. Obstet Gynecol Clin North Am 2016;43:69-81.

21. Margulies RU, Rogers MA, Morgan DM. Outcomes of transvaginal uterosacral ligament suspension: systematic review and metaanalysis. Am J Obstet Gynecol 2010;202:124-34.

22. Shull BL, Bachofen C, Coates KW, et al. A transvaginal approach to repair of apical and other associated sites of pelvic organ prolapse with uterosacral ligaments. Am J Obstet Gynecol 2000;183:1365-73; discussion 1373-4.

23. Unger CA, Walters MD, Ridgeway B, et al. Incidence of

Cite this article as: Wang W, Zhang Y, Shen W, Niu K, Lu Y. Long-term efficacy of transvaginal high-uterosacral ligament suspension for middle-compartment defect-based pelvic organ prolapse. Ann Transl Med 2020;8(24):1645. doi: 10.21037/atm20-7296

\section{Wang et al. Efficacy of high uterosacral ligament suspension}

adverse events after uterosacral colpopexy for uterovaginal and posthysterectomy vault prolapse. Am J Obstet Gynecol 2015;212:603.e1-7.

24. Jackson E, Bilbao JA, Vera RW, et al. Risk factors for ureteral occlusion during transvaginal uterosacral ligament suspension. Int Urogynecol J 2015;26:1809-14.

25. Maldonado PA, Stuparich MA, Mc Intire DD, et al.

Proximity of uterosacral ligament suspension sutures and S3 sacral nerve to pelvic landmarks. Int Urogynecol J 2017;28:77-84.

(English Language Editor: J. Chapnick) 